\title{
PESQUISAS COM TEMÁTICAS ARQUIVÍSTICAS NA CIÊNCIA DA INFORMAÇÃO: MAPEAMENTO DAS PRINCIPAIS TENDÊNCIAS
}

\author{
RESEARCHES WITH ARCHIVAL THEMES IN INFORMATION SCIENCE IN BRAZIL: \\ MAPPING OF MAIN TRENDS
}

Angelica Alves da Cunha Marques Professora do Curso de Arquivologia Doutora em Ciência da Informação Universidade de Brasília angelicacunha@unb.br

\section{Resumo}

Este trabalho apresenta parte dos resultados de uma pesquisa de doutoramento, cujo objetivo é identificar as interlocuções entre a Arquivologia mundial e a nacional a partir das tendências internacionais presentes no desenvolvimento da área no Brasil. Nesse sentido, mapeia, nas dissertações e teses com temáticas arquivísticas produzidas nos vários programas de pósgraduação em Ciência da Informação, as referências bibliográficas arquivísticas, os autores e as obras de interesse direto da área, os países, períodos e idiomas de publicação. O universo da pesquisa aqui apresentado contempla cinquenta dissertações e teses desenvolvidas em oito programas de pós-graduação em Ciência da Informação de universidades brasileiras identificadas no Banco de Teses da CAPES. A partir da análise das referências bibliográficas arquivísticas dessas pesquisas, observa-se: a sua concentração nos programas de pósgraduação em Ciência da Informação da UFMG e UnB; a predominância da sua publicação no Brasil nos anos 1990 e em português (inclusive traduções). Há uma aproximação entre o número total de autores internacionais e nacionais mapeados, embora esses últimos sutilmente se destaquem. As trinta maiores frequências de referências arquivísticas por autor corroboram esse resultado, apontando a prevalência de brasileiros e de canadenses. As trinta maiores frequências de obras citadas também se relacionam, majoritariamente, a autores brasileiros. $\mathrm{O}$ mapeamento desses indicadores, numa análise entrecruzada, reflete os movimentos das tendências internacionais em interlocução com a Arquivologia brasileira, que, embora tenha um estatuto híbrido em razão dessas tendências, já apresenta uma produção científica consolidada, fortemente comunicada a partir das referências a autores e obras nacionais citadas em dissertações e teses com temáticas na área.

Palavras-chave: Arquivologia. Ciência da Informação. Produção científica arquivística. Bibliografia arquivística.

\section{CONSIDERAÇÕES INICIAIS}

Este trabalho se insere nos propósitos de um amplo projeto de pesquisa sobre a trajetória da Arquivologia no Brasil, desenvolvido desde 2002, inicialmente como um projeto de iniciação científica (CUNHA; RODRIGUES, 2003), depois como uma dissertação (MARQUES, 2007) e, hoje, como uma tese voltada para a compreensão das interlocuções entre as práticas e o pensamento arquivístico internacional e nacional (MARQUES, 2011).
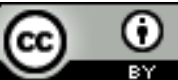
DOI 10.5007/1518-2924.2011v16nesp1p1

Enc. Bibli: R. Eletr. Bibliotecon. Ci. Inf., Florianópolis, n. esp., 1ºm. 2011. ISSNe 1518-2924. 
O estudo dessa trajetória, no Mestrado, nos apresenta a Arquivologia como uma disciplina decorrente da necessidade prática de formação de profissionais especializados para o tratamento e a organização dos arquivos do país, marcada pela atuação do Arquivo Nacional (AN), com uma tradição essencialmente histórica. No entanto, chamou-nos a atenção a atual configuração dessa disciplina, muito próxima à Ciência da Informação $(\mathrm{CI})$ em termos institucionais, quanto aos três aspectos analisados na pesquisa: a vinculação acadêmica dos cursos de Arquivologia, a formação/titulação dos seus quadros docentes e a produção de dissertações e teses com temáticas arquivísticas ou de interesse direto da área ${ }^{1}$.

A partir dessa configuração e sem perder de vista a busca por autonomia da área, voltamonos, na tese, para o estudo das relações entre a Arquivologia e a CI no Brasil, à luz do desenvolvimento da primeira no contexto internacional e considerando duas questões: 1) a constituição e o fortalecimento da CI como campo científico, após a Segunda Guerra Mundial, teria propiciado uma maior aproximação entre essa disciplina e a Arquivologia, que, como uma área tradicionalmente perpassada por uma forte vertente prática, teria passado a buscar, na CI, o desenvolvimento do seu viés acadêmico? ${ }^{2}$ 2) Com base no desenvolvimento dessas duas disciplinas e o seu papel social, os habitus e o campo científico-transcientíficodiscursivo da Arquivologia no Brasil alinhar-se-iam àqueles da CI e da própria Arquivologia internacional, relativamente aos processos de tratamento, organização, preservação, recuperação e disponibilização de informações?

Para esse estudo, tornaram-se relevantes as contribuições de alguns autores da Sociologia e Filosofia, dentre os quais destacamos alguns conceitos fundamentais para a análise do nosso objeto: habitus e campo científico de Bourdieu (2001), campo transcientifico de Knorr-Cetina (1981) e campo dos acontecimentos discursivos de Foucault (2005).

O campo científico é delineado sob duas vertentes complementares: "como outros campos, é um campo de forças, dotado de uma estrutura e também um campo de lutas para conservar ou transformar esse campo de forças". A expressão "campo de forças" verifica-se, segundo o autor:

\footnotetext{
${ }^{1}$ A maioria dos títulos é de interesse direto da área; outros a tangenciam, embora não sejam propriamente arquivísticos, como: a relação entre a História e as fontes documentais; conservação, preservação e restauração de acervos; e a harmonização do ensino das disciplinas que tem por objeto a organização e disponibilização da informação.

${ }^{2}$ Durante esse conflito, cresceram as preocupações quanto ao tratamento, ao controle e à preservação da informação, que, vertiginosamente, expandia a sua produção em todo o mundo. Com o aumento das massas documentais, intensificaram-se os estudos, os investimentos e as normas tendo em vista a sua organização e controle (DUCHEIN, 1993). Com a vitória dos Estados Unidos, essas preocupações passam a se moldar conforme o pensamento norte-americano (ou a partir dele), conforme sua repercussão internacional.

Enc. Bibli: R. Eletr. Bibliotecon. Ci. Inf., Florianópolis, n. esp., $1^{\circ}$ sem. 2011. ISSNe 1518-2924. 
[...] na relação entre os diferentes agentes (conhecidos como 'fontes de campo') que se engendram no campo e nas relações de força que o caracterizam - relação de forças específica, propriamente simbólica, sendo dada pela natureza da força capaz de se exercer nesse campo, o capital científico, espécie de capital simbólico que age na e pela comunicação. (BOURDIEU, 2001, p. 69, tradução nossa).

Como "campo de lutas", o campo científico é o produto do encontro entre duas histórias: uma história incorporada sob a forma de disposições e uma história objetivada na própria estrutura do campo e nos seus objetos técnicos (instrumentos), escritos etc. Essa história objetivada diz respeito ao habitus que perpassa o campo: a estrutura objetiva que define as condições sociais de sua produção é conjugada com as condições de exercício do "habitus como transcendental histórico", no qual ele está, a priori, como estrutura estruturada e produzida por toda uma série de aprendizagens comuns ou individuais. O campo científico tem, portanto, uma lógica própria de funcionamento, relativamente alheia à dinâmica social (o que the confere uma autonomia relativa), perpassada e caracterizada pelos habitus dos atores que os compõem.

Mais amplo e dinâmico que o campo científico, o campo transcientífico" "remete a redes de relacionamentos simbólicos que, em princípio, vão além dos limites de uma comunidade científica ou do campo científico" (KNORR-CETINA, 1981, p. 81-82, tradução nossa). Nesse sentido, a autora destaca o caráter transepistêmico, o qual diz respeito à tradução, ou seja, à negociação entre os diversos agentes em torno dos problemas da pesquisa, suas soluções e avaliações (HOCHMAN, 1994). Knorr-Cetina, então, conjuga aspectos científicos e sociais, que desencadeiam seleções definidoras da produção científica pelas instituições e pelos próprios pesquisadores.

Essa perspectiva nos parece bastante viável para o entendimento da classificação das áreas do conhecimento do Conselho Nacional de Desenvolvimento Científico e Tecnológico (CNPq) e a sua consequente política de fomento à pesquisa. No caso da Arquivologia, a instituição a concebe no âmbito da CI, o que vem causando algumas reações de pesquisadores da área, defendendo a sua autonomia em relação a essa disciplina, como observamos na dissertação (MARQUES, 2007).

O campo dos acontecimentos discursivos, por sua vez, é entendido por Foucault como:

[...] o conjunto sempre finito e efetivamente limitado das únicas sequências linguísticas que tenham sido formuladas; elas bem podem ser inumeráveis e podem, por sua massa, ultrapassar toda capacidade de registro, de memória ou de leitura: elas constituem, entretanto, um conjunto finito. (FOUCAULT, 2005, p. 30).

\footnotetext{
${ }^{3}$ Inicialmente, Knorr-Cetina utilizava a expressão campo transcientífico; depois, ela reelaborou a expressão para arena transepistêmica (HOCHMAN, 1994, p. 226). No entanto, aqui optamos pelo uso de campo transcientífico para facilitar as suas comparações com o campo cientifico, proposto por Bourdieu (2001). 
Nessa perspectiva, esse estudioso entende que os discursos carregam recortes temporais, estabelecendo ordenamentos, hierarquias e "períodos enunciativos", com, pelo menos, dois níveis de relações: 1) as primárias ou reais do discurso, dispostas conforme "condições positivas de um feixe de relações" - quem fala? De onde fala? De quais instituições? Qual a situação que ocupa? - que se fundem com 2) as relações secundárias ou reflexivas (externas ao discurso) para constituir um sistema de relações discursivas.

Diante dessas considerações, as contribuições de Foucault deixam para trás a concepção das tendências históricas do pensamento arquivístico internacional como modelos fechados e passam a compreendê-las como séries discursivas em articulação e construção num contexto maior (embora limitado) de circulação, ou seja, a do campo científico-transcientíficodiscursivo. Nessa perspectiva, essas tendências ultrapassam os limites do campo científico, concebem as interferências sócio-cognitivas no campo transcientífico, dialogam-se e se entrecruzam como enunciados entreabertos, que apreendem as práticas e saberes que estão além dos espaços da ciência, influenciados pelos movimentos sociais, econômicos, culturais e políticos na trajetória de uma disciplina, a Arquivologia.

A partir desses conceitos, importa-nos, portanto, compreender o desenvolvimento dessa disciplina no Brasil, a partir dos intercâmbios entre o pensamento e as práticas arquivísticas nacionais e internacionais, considerando de forma conjugada os seus conflitos, lutas, alianças, discursos, lógica de funcionamento.

\section{METODOLOGIA}

A pesquisa de doutorado (MARQUES, 2011) contemplou, como uma das suas etapas, o mapeamento, na Internet e nas bibliotecas universitárias, dos autores e das obras referenciados nas dissertações e teses com temáticas relacionadas à Arquivologia, identificadas na pesquisa de Mestrado (MARQUES, 2007) e atualizadas na tese, produzidas nos Programas de Pósgraduação do Brasil entre 1972 e 2006.

Primeiramente, mapeamos, no Banco de Teses da Coordenação de Aperfeiçoamento de Pessoal de Nível Superior (CAPES), dissertações e teses arquivísticas, com o uso dos descritores arquivologia, arquivística e arquivos, conforme metodologia apresentada por 
Fonseca (2004). Nessa ocasião, foram identificados, a partir dos títulos, 109 trabalhos, distribuídos em diversos programas de pós-graduação do Brasil ${ }^{4}$.

Desse total, apresentaremos a análise de 45 dissertações e cinco teses, com temáticas arquivísticas diretas ou indiretas (apêndice A), desenvolvidas em oito Programas de Pósgraduação em CI de universidades brasileiras, entre 1986 e 2006: treze na UnB; onze na Universidade Federal do Rio de Janeiro (UFRJ), em convênio com o Instituto Brasileiro de Informação em Ciência e Tecnologia (IBICT); onze na Universidade Federal de Minas Gerais (UFMG); cinco na Pontifícia Universidade Católica de Campinas (PUCCAMP); quatro na Universidade Federal Fluminense (UFF/IBICT); quatro na Universidade Estadual Paulista Júlio de Mesquita Filho (UNESP/Campus Marília); uma na Universidade Federal da Paraíba (UFPB); e uma na Universidade de São Paulo (USP).

Nesse universo, identificamos as referências bibliográficas arquivísticas das dissertações e teses da área, das quais analisamos: os autores e as obras de interesse direto da área, os países, períodos e idiomas de publicação ${ }^{5}$. Essa análise baseou-se no pré-teste apresentado como comunicação oral no Encontro Nacional de Pesquisa em Ciência da Informação (ENANCIB), quando mapeamos as referências bibliográficas das comunicações orais, também com temáticas relacionadas à área, apresentadas nesse evento entre 2003 e 2008 . Esse mapeamento permitiu a identificação da procedência institucional dos autores e o idioma de publicação das obras referenciadas, contribuindo, assim, para a compreensão do objeto principal da tese (MARQUES; RODRIGUES, 2009).

\section{RESULTADOS}

Nas 45 dissertações e cinco teses arquivísticas produzidas nos Programas de Pós-graduação em CI brasileiros, identificamos 5.260 referências bibliográficas (arquivísticas, não arquivísticas, fontes primárias e entrevistas), das quais analisaremos 2.371 (45\%), relativas às referências de obras arquivísticas ou com temáticas de interesse direto da área e que são comuns a outras disciplinas do campo da informação.

\footnotetext{
${ }^{4}$ Essa pesquisa foi feita no mestrado e repetida no doutorado a fim de atualizarmos o primeiro mapeamento. No entanto, nesse segundo momento, tivemos acesso a somente 103 dessas pesquisas, das quais analisamos se eram, de fato, arquivísticas, conforme seus títulos e referências bibliográficas.

${ }^{5}$ A tabulação foi feita em Excel 2007. No caso dos autores, países e períodos e idiomas de publicação, consideramos até três em cada caso.

Enc. Bibli: R. Eletr. Bibliotecon. Ci. Inf., Florianópolis, n. esp., $1^{\text {o }}$ sem. 2011. ISSNe 1518-2924. 


\begin{tabular}{|c|c|c|c|c|c|c|}
\hline \multirow[t]{2}{*}{ Universidade } & \multicolumn{2}{|c|}{$\begin{array}{c}\text { Quantidade de } \\
\text { dissertações e } \\
\text { teses } \\
\text { arquivísticas }\end{array}$} & \multirow[t]{2}{*}{$\begin{array}{c}\text { Total de } \\
\text { referências } \\
\text { arquivísticas }\end{array}$} & \multirow[t]{2}{*}{$\begin{array}{c}\text { Total de } \\
\text { referências } \\
\text { arquivísticas não } \\
\text { arquivísticas }\end{array}$} & \multirow[t]{2}{*}{$\begin{array}{c}\text { Fontes } \\
\text { primárias }\end{array}$} & \multirow[t]{2}{*}{ Entrevistas } \\
\hline & D* & $\mathbf{T} * *$ & & & & \\
\hline UnB & 13 & 0 & 571 & 443 & 20 & 8 \\
\hline UFRJ / IBICT & 10 & 1 & 458 & 712 & 62 & 6 \\
\hline UFMG & 9 & 2 & 523 & 722 & 8 & 1 \\
\hline PUCCAMP & 5 & 0 & 280 & 257 & 0 & 0 \\
\hline UFF / IBICT & 2 & 2 & 240 & 229 & 0 & 0 \\
\hline UNESP & 4 & 0 & 194 & 332 & 0 & 0 \\
\hline UFPB & 1 & 0 & 32 & 80 & 0 & 0 \\
\hline USP & 1 & 0 & 73 & 9 & 0 & 0 \\
\hline TOTAL & 45 & 5 & 2.371 & 2.784 & 90 & 15 \\
\hline
\end{tabular}

Tabela 1: Referências bibliográficas arquivísticas das dissertações e teses com temáticas na área dos Programas de Pós-graduação em CI (1986-2006)

Fonte: elaboração própria, com base nas dissertações e teses consultadas.

* Dissertações

** Teses

Constatamos que há uma média de $47,42 \%$ de referências arquivísticas por dissertação ou tese. Por programa de pós-graduação, essa média pode ser assim observada: UnB (43,92\%), UFRJ/IBICT (41,63\%), UFMG (47,54\%), PUCCAMP (56\%), UFF/IBICT (60\%), UNESP (48,5\%), UFPB (32\%) e USP (73\%). Considerando o número de dissertações e teses por programa, são na UFMG e UnB as maiores concentrações de referências arquivísticas por pesquisa. A maioria das referências arquivísticas foi publicada no Brasil (59,62\%), na década de $1990(44,46 \%)$, conforme apresentado nas tabelas 2 e 3. 


\section{País de publicação}

Frequência

\begin{tabular}{lc}
\hline Brasil & 1419 \\
França & 203 \\
EUA & 164 \\
Espanha & 116 \\
Canadá & 111 \\
Portugal & 80 \\
Inglaterra & 65 \\
Não identificados & 53 \\
Austrália & 40 \\
Itália & 29 \\
México & 22 \\
Argentina & 20 \\
Peru & 14 \\
Alemanha & 7 \\
Holanda & 6 \\
Suécia & 5 \\
Chile & 4 \\
Hungria & 4 \\
China & 3 \\
Bélgica & 3 \\
Inglaterra/EUA & 3 \\
Alemanha/EUA/Inglaterra/França & 3 \\
Colômbia & 3 \\
Brasil/Portugual & 2 \\
Brasil/Alemanha & 2 \\
EUA/França & 1 \\
Israel & 1 \\
Uruguai & 1 \\
TOTAL & 1 \\
\hline Tabela 2: Páses de publicac̃o das referências & 2 \\
\hline
\end{tabular}

Tabela 2: Países de publicação das referências bibliográficas arquivísticas das dissertações e teses com temáticas na área dos Programas de Pós-graduação em CI (1986-2006)

Fonte: elaboração própria, com base nas dissertações e teses consultadas. 


\begin{tabular}{lc}
\hline Período de publicação & Frequência \\
\hline Séc. XIX & 3 \\
$1921-1930$ & 4 \\
$1931-1940$ & 4 \\
$1941-1950$ & 3 \\
$1951-1960$ & 35 \\
$1961-1970$ & 55 \\
$1971-1980$ & 230 \\
$1981-1990$ & 638 \\
$1991-2000$ & 1061 \\
$2001-2009$ & 281 \\
Data imprecisa & 3 \\
Sem data & 67 \\
Trabalho não publicado & 2 \\
\hline TOTAL & 2.386
\end{tabular}

Tabela 3: Período de publicação das referências bibliográficas arquivísticas das dissertações e teses com temáticas na área dos Programas de Pós-graduação em CI (1986-2006)

Fonte: elaboração própria, com base nas dissertações e teses consultadas.

Acerca do idioma das referências arquivísticas mapeadas, podemos verificar que a maioria diz respeito a obras publicadas em português (52,25\% originais em português e $10,08 \%$ traduções para essa língua).

\begin{tabular}{c|c|c|c|c|c|c}
\hline \multirow{2}{*}{ Universidade } & \multicolumn{6}{c}{ Idioma de publicação das obras arquivísticas } \\
\cline { 2 - 7 } & \multicolumn{2}{c}{ Português } & \multicolumn{4}{c}{ Outros idiomas } \\
\cline { 2 - 7 } & Original & Tradução & Espanhol & Inglês & Francês & Italiano \\
\hline UnB & 336 & 65 & 30 & 82 & 49 & 5 \\
UFRJ / IBICT & 199 & 39 & 63 & 108 & 46 & 3 \\
UFMG & 260 & 64 & 43 & 136 & 17 & 3 \\
PUCCAMP & 186 & 30 & 16 & 14 & 31 & 3 \\
UFF / IBICT & 124 & 10 & 18 & 65 & 23 & - \\
UNESP/ Marília & 90 & 21 & 42 & 19 & 13 & 9 \\
UFPB & 25 & 3 & 3 & - & 1 & - \\
USP & 18 & 7 & 24 & 20 & 1 & 3 \\
\hline TOTAL & 1.239 & 239 & 237 & 444 & 182 & 26 \\
\hline
\end{tabular}

Tabela 4: Idiomas de publicação das referências arquivísticas das dissertações e teses com temáticas na área, por Programa de Pós-graduação (1986-2006)

Fonte: elaboração própria, com base nas dissertações e teses consultadas.

Quanto aos autores que mais aparecem nas 2.371 referências arquivísticas, 179 são reincidentes, considerando a análise por programa. Desses, 89 são internacionais e 90, nacionais. A análise das origens institucionais desses autores por programa de pós-graduação nos aponta a predominância de brasileiros na UnB (57,14\%), UFRJ/IBICT (61,9\%), 
PUCCAMP (60\%), UNESP (53,57\%) e UFPB (80\%). Nos demais programas, prevalecem autores estrangeiros: UFMG (52,7\%), UFF/IBICT $(65,51 \%)$ e USP $(71,42 \%)$.

No entanto, esses números podem nos induzir a uma análise equivocada, se não considerarmos a sua concentração. A exemplo de Vanz e Caregnato (2008), centramo-nos nas trinta maiores frequências de citação, que correspondem a 32 autores: vinte brasileiros e doze, estrangeiros, conforme tabela 5. Esses 32 autores relacionam-se a 1.089 referências, ou seja, 45,92\% das referências arquivísticas em análise. Estão concentrados na UnB (27,73\%), UFMG $(21,21 \%)$ e UFRJ/IBICT $(14,96 \%)$, onde está grande parte das referências arquivísticas (tabela 1).

Observamos que quatro autorias dizem respeito a países ou estados, o que nos remete às referências à legislação arquivística. Também constatamos quatro referências a autorias institucionais, o que reforça o papel das instituições arquivísticas, conselhos e associações profissionais no desenvolvimento da área, bem representadas pelo Arquivo Nacional, Conselho Internacional de Arquivos (ICA) e Associação dos Arquivistas Brasileiros (AAB), respectivamente.

Em relação aos autores internacionais mais referenciados, segundo suas origens institucionais, temos: canadenses (6), norte-americanos (2), francês (1), espanhol (1), inglês (1) e português (1).

As obras arquivísticas ou de interesse direto da área que são reincidentes por programa de pós-graduação no universo analisado dizem respeito a 154 obras. As trinta maiores frequências dizem respeito a 44 obras, conforme tabela 6 . Vinte e três autores dessas obras coincidem com as trinta maiores reincidências de autorias já analisadas. Os autores que mais têm obras referenciadas são: JARDIM, José Maria (7); BELLOTTO, Heloísa Liberalli (3); CAMARGO, Ana Maria de Almeida (3); COSTA, Célia Maria Leite (3); COOK, Michael (2); DOLLAR, Charles (2); FONSECA, Maria Odila (2); e SCHELLENBERG, Theodore Roosevelt (2). Ou seja, temos cinco brasileiros, dois norte-americanos e um inglês.

Nessas obras com trinta maiores frequências de referência, identificamos a predominância do português (27 brasileiras e uma portuguesa) e da tradução para essa língua (sete brasileiras e uma portuguesa). Depois vem o inglês (5), o espanhol (2) e o francês (1). 


\begin{tabular}{|c|c|c|c|c|c|c|c|c|c|}
\hline Autor & UnB & UFRJ / IBICT & UFMG & PUCCAMP & UFF / IBICT & UNESP & UFPB & USP & Total \\
\hline JARDIM, José Maria & 30 & 27 & 20 & 4 & 33 & 5 & 5 & 0 & 124 \\
\hline BELLOTTO, Heloísa Liberalli & 22 & 0 & 29 & 29 & 6 & 14 & 0 & 8 & 108 \\
\hline BRASIL & 31 & 18 & 19 & 2 & 2 & 0 & 2 & 0 & 74 \\
\hline SCHELLENBERG, Theodore Roosevelt & 10 & 13 & 12 & 8 & 6 & 5 & 2 & 4 & 60 \\
\hline FONSECA, Maria Odila Kahl & 14 & 7 & 7 & 5 & 23 & 4 & 0 & 0 & 60 \\
\hline COUTURE, Carol & 24 & 11 & 0 & 5 & 7 & 10 & 0 & 0 & 57 \\
\hline DUCHEIN, Michel & 15 & 8 & 11 & 4 & 5 & 3 & 0 & 0 & 46 \\
\hline CONSEIL INTERNATIONAL DES ARCHIVES & 8 & 4 & 21 & 3 & 3 & 3 & 0 & 2 & 44 \\
\hline DURANTI, Luciana & 0 & 9 & 11 & 2 & 13 & 8 & 0 & 0 & 43 \\
\hline HEREDIA HERRERA, Antonia & 3 & 3 & 7 & 5 & 4 & 7 & 0 & 12 & 41 \\
\hline ROUSSEAU, Jean-Yves & 10 & 11 & 4 & 4 & 4 & 7 & 0 & 0 & 40 \\
\hline CAMARGO, Ana Maria de Almeida & 6 & 4 & 8 & 9 & 4 & 8 & 0 & 0 & 39 \\
\hline LOPES, Luis Carlos & 20 & 0 & 10 & 6 & 0 & 3 & 0 & 0 & 39 \\
\hline COOK, Michael & 10 & 4 & 10 & 0 & 3 & 0 & 0 & 4 & 31 \\
\hline ARQUIVO NACIONAL & 15 & 9 & 3 & 0 & 0 & 0 & 0 & 0 & 27 \\
\hline CONSELHO NACIONAL DE ARQUIVOS & 0 & 4 & 9 & 2 & 0 & 0 & 0 & 0 & 26 \\
\hline PAES, Marilena Leite & 5 & 6 & 6 & 4 & 0 & 0 & 2 & 0 & 23 \\
\hline SILVA, Armando Malheiro da & 7 & 2 & 5 & 0 & 4 & 3 & 0 & 0 & 21 \\
\hline RODRIGUES, José Honório & 6 & 5 & 5 & 3 & 0 & 0 & 0 & 0 & 19 \\
\hline COOK, Terry & 0 & 0 & 3 & 0 & 12 & 3 & 0 & 0 & 18 \\
\hline DOLLAR, Charles M. & 7 & 0 & 4 & 0 & 4 & 2 & 0 & 0 & 17 \\
\hline BASTOS, Aurélio Wander & 5 & 5 & 3 & 0 & 4 & 0 & 0 & 0 & 17 \\
\hline DISTRITO FEDERAL & 15 & 0 & 0 & 0 & 0 & 0 & 0 & 0 & 15 \\
\hline DUCHARME, Daniel & 6 & 0 & 0 & 0 & 2 & 7 & 0 & 0 & 15 \\
\hline ASSOCIAÇÃO DOS ARQUIVISTAS BRASILEIROS & 2 & 7 & 3 & 0 & 0 & 0 & 0 & 0 & 12 \\
\hline BOSCHI, Caio César & 0 & 0 & 11 & 0 & 0 & 0 & 0 & 0 & 11 \\
\hline BRASIL. Câmara dos Deputados & 10 & 0 & 0 & 0 & 0 & 0 & 0 & 0 & 10 \\
\hline FRANCO, Celina do Amaral Peixoto Moreira & 2 & 2 & 0 & 4 & 2 & 0 & 0 & 0 & 10 \\
\hline INOJOSA, Rose Marie & 3 & 0 & 0 & 7 & 0 & 0 & 0 & 0 & 10 \\
\hline LOPEZ, André Porto Ancona & 3 & 0 & 0 & 2 & 0 & 2 & 0 & 3 & 10 \\
\hline MINAS GERAIS/Legislação do Estado & 0 & 0 & 10 & 0 & 0 & 0 & 0 & 0 & 10 \\
\hline TOTAL & 302 & 163 & 231 & 114 & 141 & 94 & 11 & 33 & 1.089 \\
\hline
\end{tabular}

Tabela 5: Trinta maiores frequências de autores reincidentes nas referências bibliográficas arquivísticas das dissertações e teses com temáticas arquivísticas dos Programas de Pósgraduação em CI (1986-2006)

Fonte: elaboração própria, com base nas dissertações e teses consultadas. 


\begin{tabular}{|c|c|c|c|c|c|c|c|c|}
\hline Obra & UnB & $\begin{array}{l}\text { UFRJ / } \\
\text { IBICT }\end{array}$ & UFMG & PUCCAMP & $\begin{array}{r}\text { UFF / } \\
\text { IBICT }\end{array}$ & $\begin{array}{l}\text { UNESP } \\
\text { (Marília) }\end{array}$ & USP & Total \\
\hline Arquivos permanentes: tratamento documental & 7 & 3 & 10 & 3 & 2 & 3 & 2 & 30 \\
\hline Arquivos modernos: princípios e técnicas & 5 & 6 & 8 & 5 & 3 & 2 & 0 & 29 \\
\hline Dicionário de Terminologia Arquivística & 7 & 4 & 5 & 0 & 2 & 4 & 0 & 22 \\
\hline Archivística general: teoria y práctica & 2 & 3 & 3 & 2 & 2 & 4 & 0 & 16 \\
\hline Registros documentais contemporâneos como provas de ação & 5 & 3 & 0 & 2 & 2 & 3 & 0 & 15 \\
\hline Lei $\mathrm{n}^{\circ} 8.159$, de 08 de janeiro de 1991 & 5 & 5 & 0 & 2 & 0 & 0 & 0 & 12 \\
\hline Os fundamentos da disciplina arquivística & 4 & 3 & 0 & 2 & 0 & 3 & 0 & 12 \\
\hline As relações entre a Arquivística e a Ciência da Informação & 0 & 4 & 0 & 0 & 4 & 3 & 0 & 11 \\
\hline A manual of archive administration & 2 & 0 & 5 & 2 & 0 & 0 & 0 & 9 \\
\hline Sistemas e políticas públicas de Arquivos no Brasil & 0 & 2 & 5 & 0 & 2 & 0 & 0 & 9 \\
\hline $\begin{array}{l}\text { Transparência e opacidade do Estado no Brasil: usos e desusos da } \\
\text { informação governamental }\end{array}$ & 5 & 0 & 2 & 0 & 2 & 0 & 0 & 9 \\
\hline A utilização acadêmica dos arquivos & 0 & 0 & 6 & 2 & 0 & 0 & 0 & 8 \\
\hline Arquivo: teoria e prática & 0 & 3 & 0 & 5 & 0 & 0 & 0 & 8 \\
\hline Cadastro Nacional de Arquivos Federais & 4 & 4 & 0 & 0 & 0 & 0 & 0 & 8 \\
\hline ISAD $(G):$ General International Standard Archival Description & 0 & 0 & 6 & 2 & 0 & 0 & 0 & 8 \\
\hline $\begin{array}{l}\text { O impacto das tecnologias de informação sobre os princípios e práticas } \\
\text { de arquivos: algumas considerações }\end{array}$ & 2 & 2 & 3 & 0 & 0 & 0 & 0 & 7 \\
\hline A formação e a pesquisa em arquivística no mundo contemporâneo & 6 & 0 & 0 & 0 & 0 & 0 & 0 & 6 \\
\hline $\begin{array}{l}\text { A importância da informação e do documento na administração pública } \\
\text { brasileira }\end{array}$ & 0 & 3 & 3 & 0 & 0 & 0 & 0 & 6 \\
\hline $\begin{array}{l}\text { A produção do conhecimento arquivístico: perspectivas nacionais e o } \\
\text { caso brasileiro (1990-1995) }\end{array}$ & 3 & 0 & 0 & 0 & 3 & 0 & 0 & 6 \\
\hline A Informação e os Arquivos: teorias e práticas & 0 & 0 & 0 & 3 & 0 & 2 & 0 & 5 \\
\hline Arquivística: teoria e prática de uma Ciência da Informação & 0 & 0 & 0 & 0 & 3 & 2 & 0 & 5 \\
\hline Dicionário Brasileiro de Terminologia Arquivística & 0 & 3 & 0 & 2 & 0 & 0 & 0 & 5 \\
\hline Direito à informação: acesso aos arquivos municipais no Brasil & 3 & 0 & 0 & 0 & 2 & 0 & 0 & 5 \\
\hline Documentos públicos e privados: arranjo e descrição & 0 & 3 & 0 & 0 & 2 & 0 & 0 & 5 \\
\hline $\begin{array}{l}\text { O respeito aos fundos em Arquivística: princípios teóricos e problemas } \\
\text { práticos }\end{array}$ & 0 & 2 & 3 & 0 & 0 & 0 & 0 & 5 \\
\hline A liberdade de informação e pesquisa & 2 & 0 & 2 & 0 & 0 & 0 & 0 & 4 \\
\hline Acesso à informação nos arquivos brasileiros & 2 & 2 & 0 & 0 & 0 & 0 & 0 & 4 \\
\hline $\begin{array}{l}\text { Algumas considerações a partir do processo de padronização da } \\
\text { descricão arquivística }\end{array}$ & 0 & 0 & 0 & 0 & 0 & 2 & 2 & 4 \\
\hline
\end{tabular}

Enc. Bibli: R. Eletr. Bibliotecon. Ci. Inf., Florianópolis, n. esp., $1^{\text {º }}$ sem. 2011. ISSNe 1518-2924. 


\begin{tabular}{|c|c|c|c|c|c|c|c|c|}
\hline Obra & UnB & $\begin{array}{l}\text { UFRJ / } \\
\text { IBICT }\end{array}$ & UFMG & PUCCAMP & $\begin{array}{r}\text { UFF / } \\
\text { IBICT } \\
\end{array}$ & $\begin{array}{l}\text { UNESP } \\
\text { (Marília) }\end{array}$ & USP & Total \\
\hline $\begin{array}{l}\text { Archives administration: a manual for a intermediate and smaller } \\
\text { organizations and for local governament }\end{array}$ & 0 & 0 & 4 & 0 & 0 & 0 & 0 & 4 \\
\hline Arquivos em sistemas nacionais de informação & 0 & 0 & 2 & 2 & 0 & 0 & 0 & 4 \\
\hline Descrição: processos e instrumentos & 0 & 0 & 0 & 2 & 0 & 0 & 2 & 4 \\
\hline $\begin{array}{l}\text { Gerenciamento arquivístico de documentos eletrônicos: uma abordagem } \\
\text { teórica da diplomática arquivística contemporânea }\end{array}$ & 0 & 0 & 2 & 0 & 2 & 0 & 0 & 4 \\
\hline Informação, Documento e Arquivo: o acesso em questão & 0 & 2 & 0 & 2 & 0 & 0 & 0 & 4 \\
\hline Information management anal archival data & 0 & 0 & 4 & 0 & 0 & 0 & 0 & 4 \\
\hline La recherche em Archivistique: un état de la question & 0 & 0 & 0 & 0 & 2 & 2 & 0 & 4 \\
\hline Manual de archivística & 0 & 0 & 2 & 0 & 0 & 2 & 0 & 4 \\
\hline Manual de conservação de documentos & 2 & 0 & 2 & 0 & 0 & 0 & 0 & 4 \\
\hline $\begin{array}{l}\text { O acesso à informação arquivística no Brasil: problemas de } \\
\text { acessibilidade e disseminação }\end{array}$ & 2 & 0 & 0 & 0 & 2 & 0 & 0 & 4 \\
\hline O conceito e a prática de gestão de documentos & 0 & 4 & 0 & 0 & 0 & 0 & 0 & 4 \\
\hline O inferno das boas intenções: legislação e políticas arquivísticas & 4 & 0 & 0 & 0 & 0 & 0 & 0 & 4 \\
\hline $\begin{array}{l}\text { O Público e o Privado: contribuição para o debate em torno da } \\
\text { caracterizaação de documentos e Arquivos }\end{array}$ & 0 & 0 & 0 & 4 & 0 & 0 & 0 & 4 \\
\hline Os arquivos nacionais: estrutura e legislação & 2 & 2 & 0 & 0 & 0 & 0 & 0 & 4 \\
\hline Guide for managing eletronic records from an archival perspective & 0 & 2 & 2 & 0 & 0 & 0 & 0 & 4 \\
\hline
\end{tabular}

Guide for managing eletronic records from an archival perspective

Tabela 6: Obras reincidentes nas referências bibliográficas arquivísticas das dissertações e teses com temáticas arquivísticas dos Programas de Pós-graduação em CI (19862006)

Fonte: elaboração própria, com base nas dissertações e teses consultadas.

\footnotetext{
${ }^{6} \mathrm{Na}$ UFPB não constatamos obras reincidentes.
} 


\section{ANÁLISE DOS RESULTADOS E CONSIDERAÇÕES FINAIS}

O mapeamento de cinquenta dissertações e teses arquivísticas produzidas em programas de pós-graduação em CI (de um total de 101) já nos indica as fortes relações, pelo menos institucionais, entre essa disciplina e a Arquivologia no Brasil. Evidentemente, a ausência de um programa de pós-graduação stricto sensu em Arquivologia no País pode justificar esse número. No entanto, não parece ser uma justificativa suficiente, uma vez que outros aspectos impulsionam o estreitamento dessa relação, de forma mais ou menos profunda. Nesse sentido, não podemos nos esquecer das questões políticas, simbólicas, cognitivas, epistemológicas e sociais que perpassam as duas disciplinas na configuração do campo científico, transcientífico e discursivo da informação, conforme os autores referenciados.

Observamos uma média equilibrada entre as referências arquivísticas $(45,07 \%)$ e não arquivísticas $(52,92 \%)^{7}$, mapeadas nas dissertações e teses analisadas, o que nos parece positivo sob o ponto de vista das interfaces tanto da Arquivologia como da CI com outras áreas. Essa constatação corrobora a hipótese da pesquisa de Mestrado, que reconhecia a interação os seus campos (ou subcampos) disciplinar e extradisciplinar da Arquivologia na sua configuração como campo científico no cenário brasileiro (MARQUES, 2007).

Quanto aos indicadores analisados no universo das referências arquivísticas, prevaleceram: autores e obras nacionais, o Brasil como país de publicação dessas obras, o português como idioma de publicação e a década de 1990, como período predominante (conforme quadro 1).

\footnotetext{
${ }^{7}$ As fontes primárias e entrevistas corresponderam a 1,99\% das referências bibliográficas totais das dissertações e teses analisadas. Na maioria dos casos esses documentos estavam incluídos nas referências bibliográficas gerais, o que corrobora a afirmação de Vanz e Caregnato (2008) de que nem sempre o mestrando ou doutorando diferencia os documentos que são fonte de pesquisa e material empírico.

Enc. Bibli: R. Eletr. Bibliotecon. Ci. Inf., Florianópolis, n. esp., 1 sem. 2011. ISSNe 1518-2924. 


\begin{tabular}{|c|c|c|c|c|c|c|c|c|}
\hline Universidade & $\begin{array}{c}\text { Média de } \\
\text { referências } \\
\text { arquivísticas por }\end{array}$ & $\begin{array}{c}\text { País de } \\
\text { publicação }\end{array}$ & $\begin{array}{l}\text { Período de } \\
\text { publicação }\end{array}$ & $\begin{array}{l}\text { Idioma de } \\
\text { publicação }\end{array}$ & $\begin{array}{l}\text { Autores } \\
\text { reincidentes } \\
\text { (total) }\end{array}$ & $\begin{array}{c}\text { Autores } \\
\text { reincidentes } \\
\text { (30 maiores }\end{array}$ & \multicolumn{2}{|c|}{$\begin{array}{c}\text { Obras reincidentes } \\
\text { (30 maiores frequências) }\end{array}$} \\
\hline UnB & $43,92 \%$ & $\begin{array}{c}\text { Brasil } \\
(69,89 \%)\end{array}$ & $\begin{array}{c}1991-2000 \\
(47,73 \%)\end{array}$ & $\begin{array}{c}\text { Português } \\
(70,57 \%)\end{array}$ & $\begin{array}{c}\text { Brasileiros } \\
(57,14 \%)\end{array}$ & $\begin{array}{c}\text { Brasileiros } \\
(64,28 \%)\end{array}$ & Nacionais $(66 \%)$ & Traduções $(23,8 \%)$ \\
\hline UFRJ / IBICT & $41,63 \%$ & $\begin{array}{c}\text { Brasil } \\
(49,34 \%) \\
\end{array}$ & $\begin{array}{c}1991-2000 \\
(41,02 \%)\end{array}$ & $\begin{array}{c}\text { Português } \\
(51,96 \%)\end{array}$ & $\begin{array}{c}\text { Brasileiros } \\
(61,9 \%)\end{array}$ & $\begin{array}{c}\text { Brasileiros } \\
(57,14 \%)\end{array}$ & Nacionais $(60 \%)$ & Traduções (30\%) \\
\hline UFMG & $47,54 \%$ & $\begin{array}{c}\text { Brasil } \\
(58,50 \%)\end{array}$ & $\begin{array}{c}1991-2000 \\
(41,68 \%)\end{array}$ & $\begin{array}{c}\text { Português } \\
(61,95 \%)\end{array}$ & $\begin{array}{c}\text { Estrangeiros } \\
(52,7 \%)\end{array}$ & $\begin{array}{c}\text { Brasileiros } \\
(58,33 \%)\end{array}$ & Nacionais (45\%) & Traduções (20\%) \\
\hline PUCCAMP & $56 \%$ & $\begin{array}{c}\text { Brasil } \\
(73,92 \%)\end{array}$ & $\begin{array}{c}1981-1990 \\
(40,35 \%)\end{array}$ & $\begin{array}{c}\text { Português } \\
(77,14 \%)\end{array}$ & $\begin{array}{c}\text { Brasileiros } \\
(60 \%)\end{array}$ & $\begin{array}{c}\text { Brasileiros } \\
(65 \%)\end{array}$ & Nacionais $(56,25 \%)$ & Traduções (25\%) \\
\hline UFF / IBICT & $60 \%$ & $\begin{array}{c}\text { Brasil } \\
(52,91 \%)\end{array}$ & $\begin{array}{c}1991-2000 \\
(46,86 \%)\end{array}$ & $\begin{array}{c}\text { Português } \\
(55,83 \%)\end{array}$ & $\begin{array}{c}\text { Estrangeiros } \\
(65,51 \%)\end{array}$ & $\begin{array}{c}\text { Estrangeiros } \\
(63,15 \%)\end{array}$ & Nacionais $(60 \%)$ & Traduções $(20 \%)$ \\
\hline UNESP & $48,5 \%$ & $\begin{array}{c}\text { Brasil } \\
(48,46 \%) \\
\end{array}$ & $\begin{array}{c}1991-2000 \\
(60,4 \%)\end{array}$ & $\begin{array}{c}\text { Português } \\
(57,21 \%)\end{array}$ & $\begin{array}{c}\text { Brasileiros } \\
(53,57 \%) \\
\end{array}$ & $\begin{array}{c}\text { Estrangeiros } \\
(64,7 \%)\end{array}$ & Nacionais $(41,66 \%)$ & Traduções (25\%) \\
\hline UFPB & $32 \%$ & $\begin{array}{c}\text { Brasil } \\
(84,37 \%) \\
\end{array}$ & $\begin{array}{c}1991-2000 \\
(50 \%)\end{array}$ & $\begin{array}{c}\text { Português } \\
(87,5 \%)\end{array}$ & $\begin{array}{c}\text { Brasileiros } \\
(80 \%) \\
\end{array}$ & $\begin{array}{c}\text { Brasileiros } \\
(75 \%) \\
\end{array}$ & - & - \\
\hline USP & $73 \%$ & $\begin{array}{c}\text { Brasil } \\
(35,61 \%)\end{array}$ & $\begin{array}{c}1991-2000 \\
(49,31 \%)\end{array}$ & $\begin{array}{c}\text { Inglês } \\
(32,87 \%)\end{array}$ & $\begin{array}{c}\text { Estrangeiros } \\
(71,42 \%)\end{array}$ & $\begin{array}{c}\text { Estrangeiros } \\
(66,66 \%)\end{array}$ & Nacionais $(100 \%)$ & Traduções $(0 \%)$ \\
\hline
\end{tabular}

Quadro 1: Indicadores predominantes nas referências bibliográficas arquivísticas das dissertações e teses com temáticas na área por programa de pós-graduação (1986-2006)

Fonte: elaboração própria, com base nas dissertações e teses consultadas. 
Observamos uma aproximação entre o número geral de autores internacionais e nacionais mapeado, embora esses últimos sutilmente se destaquem. As trinta maiores incidências de referências arquivísticas por autor ratificam esse destaque, apontando a predominância de brasileiros e de canadenses. De acordo com as conclusões decorrentes do nosso pré-teste (MARQUES; RODRIGUES, 2009), a predominância de autores brasileiros parece-nos demonstrar pelo menos duas situações: 1) a busca por obras em português, pela comodidade de leitura, que por sua vez pode ser justificada pelas dificuldades de acesso a outros idiomas; 2) e a forte influência de autores brasileiros, que, evidentemente têm produzido obras de inegável qualidade teórica, sincronizadas aos principais avanços do pensamento arquivístico internacional. Considerando que não há pós-graduação stricto sensu de Arquivologia no Brasil, esse último aspecto parece ser bastante positivo para a conquista desse espaço próprio de produção de pesquisas na área no País.

A grande ocorrência de canadenses nos remete à influência da "Arquivística Integrada", proposta que teve grande repercussão mundial nas últimas décadas do século $\mathrm{XX}$, contribuindo valiosamente para os avanços da disciplina. Essa abordagem faz uma releitura do tradicional Princípio da Proveniência, numa tentativa de reconhecer e respeitar a intenção por trás desse tradicional princípio, relacionando a informação registrada com o contexto da atividade orgânica (pessoal ou institucional). Centra-se nas propriedades do documento como testemunho de ações e transações do seu produtor e, portanto, no contexto orgânico da manutenção dos registros, de forma que se analise e avalie a importância das funções estatais, seus programas, atividades e operações - e as interações com os cidadãos - ou, seja, por que os documentos são criados. Nessa perspectiva, a avaliação deriva de uma leitura "hermenêutica" dos registros, num processo de macroavaliação, entrecruzando a análise funcional (orgânica) e a diplomática (individual) dos documentos para contextualizar a sua produção (COOK, 1997).

As contribuições de autores anglo-saxões, espanhóis, franceses e portugueses não deixam de conferir um caráter híbrido à produção científica da área no Brasil, a partir da coexistência de diversas tradições (práticas e teóricas) no cenário nacional. Parece-nos que essa hibridez é relevante para a interlocução da Arquivologia brasileira com outros países, por meio, inclusive, das traduções que favorecem uma reapropriação dos avanços internacionais da área. É, também, essa hibridez que parece flexibilizar os contornos da disciplina, permitindo que suas temáticas sejam estudadas em diferentes áreas, sem comprometer a sua identidade. 
As trinta maiores frequências de obras citadas também se relacionam, majoritariamente, a autores brasileiros e foram publicadas em português. Chama-nos a atenção que os dois autores e as duas obras mais referenciadas são de brasileiros, constatação que reforça a consolidação científica da disciplina no Brasil.

A concentração das referências arquivísticas nos programas de pós-graduação em CI da UFMG e UnB nos apresenta, no primeiro caso, o desenvolvimento de estudos propriamente arquivísticos no âmbito da pós, numa universidade que, até há pouco tempo, não possuía um curso de graduação na área ${ }^{8}$, talvez, na tentativa de se suprir essa carência. No segundo caso, o grande número de referências arquivísticas pode ser compreendido pelo compartilhamento de espaço institucional desse programa com o Curso de Arquivologia desde 1991, ano em que o esse curso entrou em funcionamento na UnB. Desse modo, é natural que docentes e egressos do Curso de Arquivologia procurem desenvolver suas pesquisas na CI e referenciem autores e obras da sua área de formação/atuação.

Por fim, entendemos que o mapeamento desses aspectos, numa análise entrecruzada, reflete os movimentos das tendências internacionais em interlocução com a Arquivologia brasileira, a qual já apresenta uma produção científica consolidada, fortemente comunicada a partir das referências a autores e obras brasileiros citados em dissertações e teses com temáticas arquivísticas.

Esses indicadores corroboram a necessidade de criação de mestrados e doutorados na área, que já deu os primeiros passos para o seu amadurecimento científico e carece, portanto, de espaços próprios para a consolidação e o aprofundamento da investigação das temáticas de seu interesse.

De toda forma, aqui, como na dissertação, defendemos que as parcerias da Arquivologia sejam mantidas e estreitadas na conformação dos seus espaços, alianças e autonomia. Evidentemente, o estatuto social que une várias disciplinas no campo da informação não poderia ser fator de isolamento. Os diálogos entre essas disciplinas dependem, em grande parte, da definição dos seus espaços comuns e particulares, ainda que delimitados por fronteiras fluidas e porosas.

${ }^{8}$ O Curso de Arquivologia da UFMG foi criado em 2008.

Enc. Bibli: R. Eletr. Bibliotecon. Ci. Inf., Florianópolis, n. esp., $1^{\text { }}$ sem. 2011. ISSNe 1518-2924. 


\section{REFERÊNCIAS}

BOURDIEU, Pierre. Science de la science et réflexivité: Cours du Collège de France 20002001. Paris: Raisons d'agir, 2001.

COOK, Terry. What is past is prologue: a History of Archival ideas since 1898, and the future paradigm shift. Archivaria, n. 43 (primavera de 1997). Disponível em: $<$ http://www.mybestdocs.com/cook-t-pastprologue-ar43fnl.htm>. Acesso em 02 set./2009.

CUNHA, Angelica Alves da; RODRIGUES, Georgete Medleg. A pesquisa em Arquivística no Brasil: um estudo da produção científica nos programas de pós-graduação e de iniciação científica e do papel das agências financiadoras. In: CONGRESSO DE INICIAÇÃO CIENTÍFICA DA UnB, 9., 2003, Brasília. Resumos... Brasília: UnB, 2003.

DUCHEIN, Michel. Archives, archivistes, Archivistique: définitions et problématique. In: FAVIER, Jean. La pratique archivistique française. Paris: Archives Nationales, 1993, p. 19-39.

FONSECA, Maria Odila. Arquivologia e Ciência da Informação: (re)definição de marcos interdisciplinares. 1997. 181 f. Tese (Doutorado em Ciência da Informação) - Universidade Federal do Rio de Janeiro, Rio de Janeiro, 2004.

FOUCAULT, Michel. A arqueologia do saber. 7 ed. Tradução Luiz Felipe Baeta Neves. Rio de Janeiro: Forense Universitária, 2005.

HOCHMAN, Gilberto. A ciência entre a comunidade e o Mercado: leituras de Kuhn, Bourdieu, Latour e Knorr-Cetina. In: PORTOCARRERO, Vera. Filosofia, História e Sociologia das Ciências I: abordagens contemporâneas. Rio de Janeiro: FIOCRUZ, 1994, p. 199-231.

KNORR-CETINA, Karin D. The manufacture of knowledge: an essay on the Constructivist and Contextual Nature of Science. Oxford: Pergamon, 1981.

MARQUES, Angelica Alves da Cunha. Os espaços e os diálogos da formação e configuração da Arquivística como disciplina no Brasil. 2007. 298 f. Dissertação (Mestrado em Ciência da Informação) - Universidade de Brasília, Brasília, 2007.

Interlocuções entre a Arquivologia nacional e a internacional no delineamento da

disciplina no Brasil. 2011. 399 f. Tese (doutorado em Ciência da Informação) Universidade de Brasília, 2011.

; RODRIGUES, Georgete Medleg. A Arquivística nos Encontros Nacionais de Pesquisa em Ciência da Informação (ENANCIB's): análise preliminar da influência do pensamento arquivístico internacional. In: ENANCIB, X, 2009, João Pessoa. Anais... João Pessoa: ANCIB, UFPB, 2009.

VANZ, Samile Andréa de Souza; CAREGNATO, Sônia Elisa. A constituição do campo da comunicação no sul do Brasil a partir da prática de comunicação científica discente. In:

Agradeço aos alunos do Curso de Arquivologia da UnB, Fernando Gabriel Corrêa, Kelly Pontes de Souza, Jaqueline de Araújo Ribeiro, Bruna de Melo Coelho e Thaiane Honda Cotts, por terem participado do Plano de Atividade Complementar, por mim orientado, auxiliando na tabulação das referências bibliográficas arquivísticas das teses e dissertações com temáticas na área. 


\begin{tabular}{|c|c|c|c|c|c|}
\hline $\begin{array}{l}\text { Universidade/ } \\
\text { Programa }\end{array}$ & Autor & $\begin{array}{l}\text { Orientador(a)/ } \\
\text { coorientador(a) }\end{array}$ & Título & $\mathbf{M} / \mathbf{D}^{*}$ & Ano \\
\hline \multirow{13}{*}{$\begin{array}{l}\text { UnB / } \\
\text { Ciência da } \\
\text { Informação }\end{array}$} & $\begin{array}{l}\text { APARÍCIO, Maria } \\
\text { Alexandra Miranda }\end{array}$ & $\begin{array}{l}\text { RODRIGUES, Georgete Medleg / } \\
\text { PANTOJA, Selma Alves }\end{array}$ & $\begin{array}{l}\text { O acesso e a utilização da informação arquivística sobre a África no Arquivo do } \\
\text { Itamaraty em Brasília }\end{array}$ & M & 2001 \\
\hline & $\begin{array}{l}\text { CARVALHÊDO, } \\
\text { Shirley do Prado }\end{array}$ & RODRIGUES,Georgete Medleg & $\begin{array}{l}\text { O Arquivo Público do Distrito Federal: contextos, concepções e práticas } \\
\text { informacionais na trajetória de uma instituição arquivística }\end{array}$ & M & 2003 \\
\hline & $\begin{array}{l}\text { GOMES, Neide } \\
\text { Aparecida }\end{array}$ & $\begin{array}{l}\text { MIRANDA, Antonio Lisboa } \\
\text { Carvalho de }\end{array}$ & $\begin{array}{l}\text { O ensino de conservação, preservação e restauração de acervos documentais no } \\
\text { Brasil }\end{array}$ & M & 2000 \\
\hline & $\begin{array}{c}\text { HOTT, Daniela } \\
\text { Francescutti Martins }\end{array}$ & RODRIGUES, Georgete Medleg & $\begin{array}{l}\text { O acesso aos documentos sigilosos: um estudo das comissões permanentes de } \\
\text { avaliação e de acesso nos arquivos brasileiros }\end{array}$ & M & 2005 \\
\hline & $\begin{array}{l}\text { MENDES, Eliane } \\
\text { Manhães } \\
\end{array}$ & $\begin{array}{l}\text { MIRANDA, Antônio Lisboa } \\
\text { Carvalho de }\end{array}$ & $\begin{array}{l}\text { Tendências para a harmonização de programas de ensino de Arquivologia, } \\
\text { Biblioteconomia e Museologia no Brasil: um estudo Delfos }\end{array}$ & M & 1992 \\
\hline & $\begin{array}{l}\text { OLIVEIRA, Eliane } \\
\text { Braga de }\end{array}$ & ALVARENGA, Lídia & $\begin{array}{l}\text { A contratação de terceiros nos serviços arquivísticos da Administração Pública } \\
\text { Federal em Brasília }\end{array}$ & M & 1997 \\
\hline & $\begin{array}{l}\text { PICCININI, Élvio } \\
\text { José }\end{array}$ & ANTUNES, Walda de Andrade & $\begin{array}{l}\text { Impacto da tecnologia da informação na atividade dos arquivos bancários: um } \\
\text { estudo de caso }\end{array}$ & M & 2001 \\
\hline & $\begin{array}{l}\text { SANTOS, Vanderlei } \\
\text { Batista dos }\end{array}$ & RODRIGUES, Georgete Medleg & $\begin{array}{l}\text { Gestão de documentos eletrônicos sob a ótica arquivística: identificação das } \\
\text { principais correntes teóricas, legislação e diagnóstico da situação nos Arquivos } \\
\text { públicos brasileiros }\end{array}$ & M & 2001 \\
\hline & $\begin{array}{l}\text { SOUSA, Renato } \\
\text { Tarciso Barbosa de }\end{array}$ & LOPES, Luis Carlos & $\begin{array}{l}\text { Arquivos ativos e massas documentais acumuladas na Administração Pública } \\
\text { Brasileira: busca de novas soluções para velhos problemas }\end{array}$ & M & 1995 \\
\hline & $\begin{array}{l}\text { GUEDES, Mario } \\
\text { Augusto Muniz }\end{array}$ & RODRIGUES, Georgete Medleg & $\begin{array}{l}\text { Riscos de perda de documentos eletrônicos de caráter arquivístico em uma } \\
\text { instituição do poder legislativo: um estudo de caso na Câmara dos Deputados }\end{array}$ & M & 2006 \\
\hline & FARIA, Wadson Silva & RODRIGUES, Georgete Medleg & $\begin{array}{l}\text { A normalização dos instrumentos de gestão arquivística no brasil: um estudo da } \\
\text { influência das resoluções do conarq na organização dos arquivos da justiça } \\
\text { eleitoral brasileira }\end{array}$ & $\mathrm{M}$ & 2006 \\
\hline & $\begin{array}{l}\text { SANTOS, Cristian } \\
\text { José Oliveira }\end{array}$ & RODRIGUES, Georgete Medleg & $\begin{array}{l}\text { Os arquivos das primeiras prelazias e dioceses brasileiras no contexto da } \\
\text { legislação e práticas arquivísticas da Igreja Católica }\end{array}$ & M & 2005 \\
\hline & $\begin{array}{l}\text { MOTTA, Mary } \\
\text { Teixeira da }\end{array}$ & COUTO, Luiz Mário Marques & $\begin{array}{l}\text { A produção da documentação diplomática: uma análise preliminar do fluxo da } \\
\text { informação embaixada-ministério-arquivo }\end{array}$ & M & 1986 \\
\hline \multirow{4}{*}{$\begin{array}{l}\text { UFRJ/IBICT } \\
\text { Ciências da } \\
\text { Informação }\end{array}$} & BOTTINO, Mariza & SOUZA, Rosali Fernandez de & $\begin{array}{l}\text { Arquivo Universitário: considerações em torno da questão. Panorama da } \\
\text { situação no Brasil }\end{array}$ & M & 1994 \\
\hline & $\begin{array}{l}\text { FONSECA, Maria } \\
\text { Odila Kahl }\end{array}$ & $\begin{array}{l}\text { GONZÁLEZ DE GOMEZ, Maria } \\
\text { Nelida }\end{array}$ & Direito à informação: acesso aos arquivos públicos municipais & M & 1996 \\
\hline & $\begin{array}{l}\text { FREITAS, Adda } \\
\text { Drugg de }\end{array}$ & $\begin{array}{l}\text { FRANCISCONI Clovis; SOUZA } \\
\text { Paulo Roberto Vauthier de }\end{array}$ & Processamento de informações de registros médico-hospitalares & M & 1972 \\
\hline & $\begin{array}{l}\text { GOMES, Sandra } \\
\text { Lucia Rebel }\end{array}$ & $\begin{array}{l}\text { GONZÁLEZ DE GOMEZ, Maria } \\
\text { Nelida }\end{array}$ & $\begin{array}{l}\text { Lugares de memória e informação: os arquivos e centros de documentação sobre } \\
\text { trabalho, trabalhadores e suas organizações }\end{array}$ & M & 1996 \\
\hline
\end{tabular}

Enc. Bibli: R. Eletr. Bibliotecon. Ci. Inf., Florianópolis, n. esp., 1º sem. 2011. ISSNe 1518-2924. 18 


\begin{tabular}{|c|c|c|c|c|c|}
\hline $\begin{array}{l}\text { Universidade/ } \\
\text { Programa }\end{array}$ & Autor & $\begin{array}{l}\text { Orientador(a)/ } \\
\text { coorientador(a) }\end{array}$ & Título & $\mathbf{M} / \mathbf{D}^{*}$ & Ano \\
\hline & JARDIM, José Maria & MARTELETO, Regina Maria & $\begin{array}{l}\text { Cartografia de uma ordem imaginária: uma análise do sistema nacional de } \\
\text { arquivos }\end{array}$ & M & 1994 \\
\hline & JARDIM, José Maria & $\begin{array}{l}\text { GONZÁLEZ DE GOMEZ, Maria } \\
\text { Nelida }\end{array}$ & Os arquivos (in)visíveis: a opacidade informacional do Estado Brasileiro & $\mathrm{D}$ & 1998 \\
\hline & $\begin{array}{l}\text { KURTZ, Clara Marli } \\
\text { Scherer }\end{array}$ & $\begin{array}{l}\text { SOUZA, Rosali Fernandes de; } \\
\text { CARVALHO, Katia de }\end{array}$ & $\begin{array}{l}\text { O Usuário do Arquivo Nacional e o seu relacionamento com os serviços } \\
\text { oferecidos para a satisfação de suas necessidades de informação }\end{array}$ & M & 1990 \\
\hline & $\begin{array}{l}\text { LASMAR, Denise } \\
\text { Portugal }\end{array}$ & $\begin{array}{l}\text { FREIRE, Isa Maria; SOUZA, } \\
\text { Rosali Fernandez de }\end{array}$ & $\begin{array}{l}\text { Estoques de informação: o acervo imagético da Comissão Rondon no Museu do } \\
\text { Índio como fonte de informação }\end{array}$ & M & 2002 \\
\hline & $\begin{array}{l}\text { RONDINELLI, } \\
\text { Rosely Curi }\end{array}$ & $\begin{array}{l}\text { JARDIM, José Maria; } \\
\text { GONZÁLEZ DE GÓMEZ, Maria } \\
\text { Nélida } \\
\end{array}$ & $\begin{array}{l}\text { O gerenciamento do documento eletrônico: uma abordagem técnica da } \\
\text { diplomática arquivística contemporânea }\end{array}$ & M & 2002 \\
\hline & $\begin{array}{l}\text { SILVA, Junia Gomes } \\
\text { da Costa Guimarães e }\end{array}$ & CHRISTOVÃO, Heloisa Tardin & $\begin{array}{l}\text { Socialização da informação arquivística: a viabilidade do enfoque participativo } \\
\text { na transferência de informação }\end{array}$ & M & 1996 \\
\hline & $\begin{array}{l}\text { SOUZA, Rosale de } \\
\text { Mattos }\end{array}$ & $\begin{array}{l}\text { CORDEIRO, Geraldo Prado e } \\
\text { Rosa Inês de Novaes }\end{array}$ & $\begin{array}{l}\text { A representação do filme documentário institucional: testemunho histórico- } \\
\text { científico no espaço informacional acadêmico }\end{array}$ & M & 2001 \\
\hline \multirow{8}{*}{$\begin{array}{l}\text { UFMG / } \\
\text { Ciência da } \\
\text { Informação }\end{array}$} & $\begin{array}{l}\text { CORTES, Maria } \\
\text { Regina Persechini } \\
\text { Armond }\end{array}$ & CARDOSO, Ana Maria Pereira & $\begin{array}{l}\text { Arquivo Público e informação: acesso à informação nos arquivos públicos } \\
\text { estaduais do Brasil }\end{array}$ & $\mathrm{M}$ & 1996 \\
\hline & $\begin{array}{l}\text { COTTA, André } \\
\text { Henrique Guerra }\end{array}$ & $\begin{array}{l}\text { CASTAGNA Paulo Augusto; } \\
\text { SANTOS, Vilma Moreira dos }\end{array}$ & O tratamento da informação em acervos de manuscritos musicais brasileiros & M & 2000 \\
\hline & $\begin{array}{l}\text { CRUZ, Emília } \\
\text { Barroso }\end{array}$ & PAIM, Isis & $\begin{array}{l}\text { Memória governamental e utilização de documentos eletrônicos pela } \\
\text { administração pública do Brasil: o caso da Secretaria de Estado da Fazenda de } \\
\text { Minas Gerais }\end{array}$ & $\mathrm{M}$ & 2002 \\
\hline & $\begin{array}{l}\text { FREITAS, Maria } \\
\text { Cristina Vieira de }\end{array}$ & SANTOS, Vilma Moreira dos & $\begin{array}{l}\text { Tudo passa e tudo fica no caminho que se faz: um estudo qualitativo de acervo e } \\
\text { fundo de arquivo de instituição cultural, sob o paradigma que insere a } \\
\text { arquivologia no contexto de uma Ciência da Informação }\end{array}$ & M & 2003 \\
\hline & $\begin{array}{l}\text { GOMES, Maria do } \\
\text { Carmo Alvarenga } \\
\text { Andrade }\end{array}$ & $\begin{array}{l}\text { FONTES, Lucy Gonçalves / } \\
\text { BOSCHI, Caio César }\end{array}$ & $\begin{array}{l}\text { A produção do conhecimento histórico e do documento: estudo da relação entre } \\
\text { a historiografia mineira e as fontes - } 1979 / 1990\end{array}$ & M & 1994 \\
\hline & $\begin{array}{l}\text { MOTTA, Vera Maria } \\
\text { Rocha V. }\end{array}$ & $\begin{array}{c}\text { FONTES, Lucy Gonçalves / } \\
\text { DELGADO, Lucília de Almeida } \\
\text { Neves }\end{array}$ & $\begin{array}{l}\text { Arquivos privados de titulares mineiros - 1930/1983: um estudo sobre a } \\
\text { localização, composição e uso dos documentos }\end{array}$ & M & 1993 \\
\hline & $\begin{array}{l}\text { NEVES, Marta Eloísa } \\
\text { Melgaço }\end{array}$ & $\begin{array}{l}\text { HARGREAVES, Lucy Gonçalves } \\
\text { Fontes }\end{array}$ & $\begin{array}{l}\text { Em busca da organicidade: um estudo do Fundo da Secretaria de Governo da } \\
\text { Capitania de Minas Gerais }\end{array}$ & M & 1997 \\
\hline & $\begin{array}{l}\text { PEDRAS, Beatriz } \\
\text { Junqueira }\end{array}$ & $\begin{array}{l}\text { SANTOS, Vilma Moreira dos / } \\
\text { ROMEIRO, Adriana }\end{array}$ & $\begin{array}{l}\text { Uma leitura do I Livro de Tombo do Convento do Carmo em Salvador: } \\
\text { contribuição à construção histórica da Ordem dos Carmelitas na Bahia-Colonial }\end{array}$ & M & 2000 \\
\hline
\end{tabular}

Enc. Bibli: R. Eletr. Bibliotecon. Ci. Inf., Florianópolis, n. esp., $1^{\circ}$ sem. 2011. ISSNe 1518-2924. 


\begin{tabular}{|c|c|c|c|c|c|}
\hline $\begin{array}{l}\text { Universidade/ } \\
\text { Programa }\end{array}$ & Autor & $\begin{array}{l}\text { Orientador(a)/ } \\
\text { coorientador(a) }\end{array}$ & Título & $\mathbf{M} / \mathbf{D}^{*}$ & Ano \\
\hline & $\begin{array}{l}\text { RODRIGUES, Ana } \\
\text { Márcia Lutterbach }\end{array}$ & SANTOS, Vilma Moreira dos & Uma análise da teoria dos arquivos & M & 2004 \\
\hline & $\begin{array}{l}\text { THOMAZ, Katia de } \\
\text { Pádua }\end{array}$ & $\begin{array}{l}\text { ANDRADE, Maria Eugênia } \\
\text { Albino }\end{array}$ & $\begin{array}{l}\text { A preservação de documentos eletrônicos de caráter arquivístico: novos } \\
\text { desafios, velhos problemas }\end{array}$ & $\mathrm{D}$ & 2004 \\
\hline & $\begin{array}{l}\text { MORENO, Nádina } \\
\text { Aparecida }\end{array}$ & $\begin{array}{l}\text { SANTOS, Vilma Moreira dos / } \\
\text { BARBOSA, Ricardo Rodrigues }\end{array}$ & $\begin{array}{l}\text { A informação arquivística no processo de tomada de decisão em organizações } \\
\text { universitárias }\end{array}$ & $\mathrm{D}$ & 2006 \\
\hline \multirow{5}{*}{$\begin{array}{l}\text { PUCCAMP } \\
\text { Ciência da } \\
\text { Informação }\end{array}$} & $\begin{array}{l}\text { CARVALHO, } \\
\text { Elizabeth Leão de }\end{array}$ & LONGO, Rose Mary Juliano & $\begin{array}{l}\text { Informação orgânica: recursos estratégicos para tomada de decisão pelos } \\
\text { membros do Conselho de Administração da Universidade Estadual de Londrina }\end{array}$ & M & 2001 \\
\hline & $\begin{array}{c}\text { GUIMARÃES, Maria } \\
\text { de Fátima }\end{array}$ & VALIO, Else Benetti Marques & $\begin{array}{l}\text { Arquivo: esse obscuro objeto do desejo. Uma metodologia para recuperação de } \\
\text { informação em autos do judiciário }\end{array}$ & M & 1995 \\
\hline & $\begin{array}{l}\text { PEREIRA, Sandra } \\
\text { Lucia }\end{array}$ & WITTER, Geraldina Porto & O conceito de arquivo na literatura e na opinião de gestores de arquivos privados & M & 1995 \\
\hline & $\begin{array}{l}\text { ZANATA, Marisa } \\
\text { Marques }\end{array}$ & VALIO, Else Benetti Marques & Instrumentos de pesquisa nos arquivos da UNICAMP & M & 1997 \\
\hline & $\begin{array}{l}\text { OLIVEIRA, Luciani } \\
\text { Aparecida de }\end{array}$ & KOBASHI, Nair Yumiko & $\begin{array}{l}\text { Aspectos teóricos, metodológicos e pragmáticos da elaboração de plano de } \\
\text { classificação arquivística para instituição privada de ensino superior }\end{array}$ & M & 2005 \\
\hline \multirow{4}{*}{$\begin{array}{l}\text { UFF/IBICT } \\
\text { Ciência da } \\
\text { Informação }\end{array}$} & $\begin{array}{l}\text { FONSECA, Maria } \\
\text { Odila }\end{array}$ & $\begin{array}{l}\text { GONZÁLEZ DE GOMEZ, Maria } \\
\text { Nelida }\end{array}$ & $\begin{array}{llllllll}\begin{array}{l}\text { Arquivologia e } \\
\text { interdisciplinares }\end{array} & \text { Ciência } & \text { da } & \text { Informação: } & \text { (re)definição } & \text { de } & \text { marcos } \\
\end{array}$ & $\mathrm{D}$ & 2004 \\
\hline & BECK, Ingrid & FONSECA, Maria Odila & $\begin{array}{l}\mathrm{O} \text { ensino da preservação documental nos cursos de Arquivologia e } \\
\text { Biblioteconomia: perspectivas para formar um novo profissional }\end{array}$ & M & 2006 \\
\hline & $\begin{array}{l}\text { OLIVEIRA, Lucia } \\
\text { Maria Velloso de }\end{array}$ & JARDIM, José Maria & $\begin{array}{l}\text { O usuário como agente no processo de transferência dos conteúdos } \\
\text { informacionais arquivísticos }\end{array}$ & M & 2006 \\
\hline & $\begin{array}{l}\text { MARIZ, Anna Carla } \\
\text { Almeida }\end{array}$ & JARDIM, José Maria & Arquivos públicos brasileiros: a transferência da informação na Internet & $\mathrm{D}$ & 2005 \\
\hline \multirow{4}{*}{$\begin{array}{l}\text { UNESP } \\
\text { Ciência da } \\
\text { Informação }\end{array}$} & $\begin{array}{l}\text { NASCIMENTO, } \\
\text { Lúcia Maria Barbosa } \\
\text { do }\end{array}$ & $\begin{array}{l}\text { GUIMARÃES, José Augusto } \\
\text { Chaves }\end{array}$ & A dimensão diplomática do documento jurídico digital & M & 2002 \\
\hline & $\begin{array}{l}\text { ALBUQUERQUE, } \\
\text { Ana Cristina de }\end{array}$ & $\begin{array}{l}\text { MARAÑON, Eduardo Ismael } \\
\text { Murguia }\end{array}$ & $\begin{array}{l}\text { Catalogação e descrição de documentos fotográficos em bibliotecas e arquivos: } \\
\text { uma aproximação comparativa dos códigos AACR2 e ISAD }(\mathrm{g})\end{array}$ & M & 2006 \\
\hline & $\begin{array}{l}\text { MONÇÃO, Jane } \\
\text { Lessa }\end{array}$ & $\begin{array}{l}\text { GUIMARÃES, José Augusto } \\
\text { Chaves }\end{array}$ & $\begin{array}{l}\text { O conceito assunto na Arquivística: uma reflexão em arquivos permanentes a } \\
\text { partir do evento - I SOGGETTI e ALTRI APPARATI di INDICIZZAZIONE IN } \\
\text { ARCHIVISTICA: ipotesi di lavoro }\end{array}$ & M & 2006 \\
\hline & $\begin{array}{l}\text { REGISTRO, Tânia } \\
\text { Cristina }\end{array}$ & $\begin{array}{l}\text { MARAÑON, Eduardo Ismael } \\
\text { Murguia }\end{array}$ & $\begin{array}{l}\text { O arranjo de fotografias em unidades de informação: fundamentos teóricos e } \\
\text { aplicações práticas a partir do Fundo José Pedro Miranda do Arquivo Público e } \\
\text { Histórico de Ribeirão Preto }\end{array}$ & M & 2005 \\
\hline
\end{tabular}

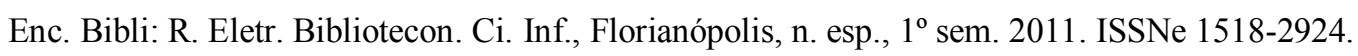




\begin{tabular}{|c|c|c|c|c|c|}
\hline $\begin{array}{c}\text { Universidade/ } \\
\text { Programa }\end{array}$ & Autor & $\begin{array}{l}\text { Orientador(a) / } \\
\text { coorientador(a) }\end{array}$ & Título & $\mathbf{M} / \mathbf{D}^{*}$ & Ano \\
\hline $\begin{array}{c}\text { UFPB } \\
\text { Ciências da } \\
\text { Informação }\end{array}$ & $\begin{array}{l}\text { MELO, Josemar } \\
\text { Henrique de }\end{array}$ & SILVA, Sílvia Cortez & Política do silêncio: o Sistema de Arquivos do Estado de Pernambuco & $\mathrm{M}$ & 1999 \\
\hline $\begin{array}{c}\text { USP } \\
\text { Ciência da } \\
\text { Informação }\end{array}$ & $\begin{array}{l}\text { LEÃO, Flávia } \\
\text { Carneiro }\end{array}$ & SMIT, Johanna Wilhelmina & $\begin{array}{l}\text { A representação da informação arquivística permanente: a normalização } \\
\text { descritiva e a } \operatorname{ISAD}(G)\end{array}$ & M & 2006 \\
\hline
\end{tabular}

APÊENDICE A: Dissertações e teses com temáticas relacionadas à Arquivística (1986 a 2006)

Fonte: elaboração própria, com base no banco de teses da CAPES, na pesquisa de Fonseca (2004) e nas dissertações e teses consultadas.

* Mestrado ou Doutorado. 


\begin{abstract}
This work presents part of the results of a doctor degree dissertation's research, whose goal is to identify the dialogues between global and Brazilian Archival Sciences, from the international trends present in the development of this field in Brazil. This way, it maps, in the dissertations and theses with Archival Science themes produced in several post-graduate programmes in Information Science, the following: Archival Science's bibliographic references, the authors and works that directly concern the field, their countries of institutional origin, and their time and language of publication. The research universe hereby presented comprehends fifty dissertations and theses developed in eight Information Science postgraduate programmes from Brazilian universities, identified in CAPES's Theses Database. From the analyses on Archival Science's bibliographic references in these researches, we observed the following: a concentration of Information Science post-graduate programmes in the Federal University of Minas Gerais (UFMG) and in the University of Brasília (UnB); and the predominance of their publication in Brazil in the 1990s and in Portuguese (including translations). There is a close tie between the total number of international and national authors mapped, although the latter slightly outnumbers the former. The thirty highest frequencies of Archival Science's bibliographic references by author corroborate this result, pointing out the prevalence of Brazilian and Canadian authors. The thirty highest frequencies of works cited also related, in its majority, to Brazilian authors. The mapping of these indicators, in a crossed analysis, reflects the movements of international trends in dialogue with Brazilian Archival Science, which, however having a hybrid regulation due to these trends, already presents a consolidated scientific production, strongly communicated from the references to Brazilian authors and works cited in dissertations and theses with themes in this field.
\end{abstract}

Keywords: Archival Science. Information Science. Archival Science's scientific production. Archival Science's bibliographic references.

Originais recebidos em: 03/10/2010

Aceito para publicação em: 15/12/2010 